\title{
Chronic symptomatic and microfilaremic loiasis in a returned traveller
}

\author{
Courtney Thompson BSC MD, Ajith Cy MBBS MD, Andrea K. Boggild MSc MD
}

A 24-year-old woman presented for evaluation of eosinophilia (4.3 [normal $\left.0.04-0.4] \times 10^{9} / \mathrm{L}\right)$, generalized pruritis and recurrent migratory swelling of the wrists. Her symptoms had begun six months after her return from a three-week stay in rural Cameroon, and had been ongoing for three years. Owing to the epidemiologic and clinical history compatible with loiasis, a blood smear was submitted for microscopic examination, which confirmed the presence of Loa loa microfilariae (microfilaremia).

While waiting for treatment with medications available only through the Special Access Programme of Health Canada, the patient presented to the emergency department with the sensation of a foreign body in her left eye (Figure 1), and was found to have a nemotode migrating in the conjunctiva. She was given albendazole to reduce the microfilarial burden, then diethylcarbamazine for definitive treatment of the adult nematodes, along with prednisone to reduce the adverse effects of treatment and the risk of encephalopathy. The patient's symptoms abated and her eosinophil count returned to normal.

Loiasis is caused by a migratory filarial nematode, Loa loa, which is transmitted to humans by Chrysops (deer) flies. ${ }^{1}$ Loiasis occurs in the central African rainforest regions of Gabon, Cameroon, Central African Republic, Democratic Republic of the Congo and Congo, with focal areas of endemicity in Nigeria, Angola and Sudan. ${ }^{2}$ Symptoms are caused by the migration of adult worms within the skin and angioedema (Calabar swellings). Migration of adults across the eye manifests as a foreign body sensation; a worm moving across the conjunctiva may be noted in about $50 \%$ of cases. ${ }^{3}$

Clinical features differ between patients who live in endemic regions and those who were born outside but travel to endemic regions. ${ }^{4}$ Our patient's case is notable because, although symp-

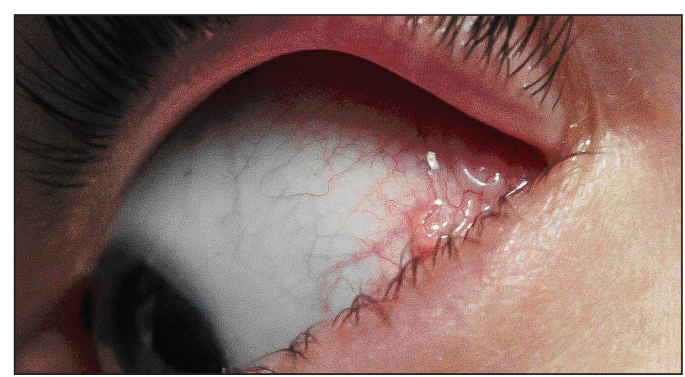

Figure 1: Adult stage of the filarial nematode Loa loa migrating in the conjunctiva of the left eye of a 24-year-old woman who had travelled to Cameroon.

tomatic disease is more common among shortterm travellers, the presence of microfilaremia is more consistently seen in patients from endemic areas who often show no symptoms. Microfilaremia is not commonly seen in expatriates or travellers born in nonendemic areas.

Infectious causes of migratory skin lesions and eosinophilia are primarily parasitic (e.g., strongyloidiasis, gnathostomiasis, paragonimiasis and toxocariasis). ${ }^{5}$ Autoimmune and noninfectious conditions that show similar migratory edematous skin changes are less likely to have associated eosinophilia (Appendix 1, www.cmaj .ca/lookup/suppl/doi:10.1503/cmaj.140609/-/

DC1). ${ }^{5}$ All patients with loiasis should be referred to a centre with expertise in the management of this complex parasitic disease.

\section{References}

1. Boussinesq M. Loiasis. Ann Trop Med Parasitol 2006;100:715-31.

2. Zouré HGM, Wanji S, Noma M, et al. The geographic distribution of Loa loa in Africa: results of large-scale implementation of the rapid assessment procedure for loiasis (RAPLOA). PLoS Negl Trop Dis 2011;5:e1210.

3. Antinori S, Schifanella L, Million M, et al. Imported Loa loa filariasis: three cases and a review of cases reported in non-endemic countries in the past 25 years. Int J Infect Dis 2012;16:e649-62.

4. Klion AD, Massougbodji A, Sadeler BC, et al. Loiasis in endemic and nonendemic populations: immunologically mediated differences in clinical presentation. J Infect Dis 1991;163:1318-25.

5. Van Dellen RG, Maddox DE, Dutta EJ. Masqueraders of angioedema and urticaria. Ann Allergy Asthma Immunol 2002; $88: 10-14$
Competing interests: None declared.

This article has been peer reviewed.

The authors have obtained patient consent.

Affiliations: Department of Medicine (Thompson, Cy, Boggild), University of Toronto; Public Health Ontario Laboratories (Boggild), Public Health Ontario; Tropical Disease Unit, Division of Infectious Diseases (Boggild), University Health NetworkToronto General Hospital, Toronto, Ont.

Correspondence to: Andrea Boggild, andrea.boggild@utoronto.ca

CMAJ 2015. DOI:10.1503 /cmaj.140609 